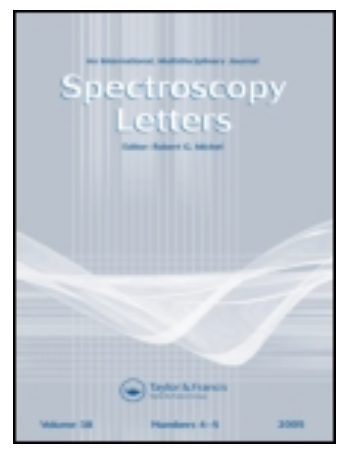

Spectroscopy Letters

An International Journal for Rapid Communication

ISSN: 0038-7010 (Print) 1532-2289 (Online) Journal homepage: http://www.tandfonline.com/loi/lstl20

\title{
Application of Raman Spectroscopy for Differentiation Among Cotton and Viscose Fibers Dyed with Several Dye Classes
}

\section{Jolanta Was-Gubala \& Waldemar Machnowski}

To cite this article: Jolanta Was-Gubala \& Waldemar Machnowski (2014) Application of Raman Spectroscopy for Differentiation Among Cotton and Viscose Fibers Dyed with Several Dye Classes, Spectroscopy Letters, 47:7, 527-535, DOI: 10.1080/00387010.2013.820760

To link to this article: http://dx.doi.org/10.1080/00387010.2013.820760

Accepted author version posted online: 24 Jul 2013.

Submit your article to this journal $₫$

ЏII Article views: 124

Q View related articles $\llbracket$

View Crossmark data ־

Citing articles: 4 View citing articles $\longleftarrow$ 


\section{Application of Raman Spectroscopy for Differentiation Among Cotton and Viscose Fibers Dyed with Several Dye Classes}

\author{
Jolanta Was-Gubala ${ }^{1}$ \\ and Waldemar Machnowski ${ }^{2}$ \\ ${ }^{1}$ Criminalistic Department, \\ Institute of Forensic Research, \\ Krakow, Poland \\ ${ }^{2}$ Lodz University of Technology, \\ Faculty of Material Technologies \\ and Textile Design, Zeromskiego, \\ Lodz, Poland
}

\begin{abstract}
The difference between natural and regenerated cellulose fibers caused by variations in the degree of polymerization and supramolecular structure, influences dyes adsorption properties. The aim of the study was to discriminate between cotton and viscose fibers, dyed with several dye classes, using Raman spectroscopy. 8 reactive and 6 direct dyes were used for colouring textiles under laboratory conditions. Spectra of fibers were obtained with the use of three excitation sources: 514, 633, and $785 \mathrm{~nm}$. The obtained results allowed for the differentiation of studied types of cellulose fibers, dyed with the same dye, at the same or very similar concentrations.
\end{abstract}

KEYWORDS dye, forensic, identification, textile fibre

\section{INTRODUCTION}

Cellulosic fibers, because of their suitability for many kinds of textile products intended for numerous purposes, are widely used practically in all parts of the world, primarily for the manufacture of textiles clothing, underwear, bed linens, towels, medical textiles, and some types of products intended for the interior of buildings. In recent years, world production of textiles of cellulose fibers has been 27-29 million tons per year, which means that the cellulose fibers in terms of consumption occupy second place among all textile raw materials (first place is taken by polyester fibers). According to the origin, all the cellulose fibers can be classified into two groups:

1. Natural, vegetable fibers (cotton, hemp, flax, jute, etc.)

2. Regenerated cellulose fibers, which are made from wood pulp or cotton linters by the derivatization of cellulose using carbon disulfide (viscose rayon) or by the solution of cellulose in $\mathrm{N}$-methylmorpholine-N-oxide (lyocell fibers)

The most important representatives of the first and second fibers group are, respectively, cotton and viscose.

Chemically, raw cotton fibers consist of about 88\%-96\% cellulose, $0.7 \%-$ $1.2 \%$ pectins, $0.4 \%-1.0 \%$ wax, $1.1 \%-1.9 \%$ proteins, and other organic and inorganic compounds. The significant part of noncellulosic components of 
cotton fibers must be removed during the fabrics' preparation for the dyeing process. This occurs during scouring and bleaching processes, which make gray cotton fabrics suitable not only for dyeing but also for other types of finishing.

Viscose fibers are obtained from wood pulp by a complicated chemical process. Cellulose xanthate, soluble in an alkali solution, after extrusion through a spinnerette into a coagulating bath, is regenerated into cellulose. The manufacturing process of viscose fibers eliminates noncellulosic natural impurities that occur in cotton fibers. Thus, the preparing process for dyeing viscose fabric is easier than in the case of cotton fabrics.

The differences between natural and regenerated cellulose fibers are, above all, in the degree of polymerization (DP) and the supramolecular structure. These differences cause different adsorption properties of dyes within the fiber. However, the same chemical nature of cotton and viscose fibers means that the same dye classes may be used for dyeing the textile products from these fibers. Most often these are direct and reactive dyes.

Direct dyes are water soluble; because of their structure, they have a good substantivity to cellulosic fibers (especially cotton). Direct dyes are bound to cellulosic fibers by physical forces such as hydrogen bonds and van der Waals forces. Aftertreatment of textiles dyed with direct dyes is used to improve their washfastness. For this purpose, different chemicals such as cationic agents are applied. ${ }^{[1,2]}$

Reactive dyes are water soluble; due to their electrophilic structure with a good leaving group (e.g., halogen, sulfate), they can react with the hydroxyl groups of cellulose and form, through esterification or etherification, covalent bonds between the dye molecules and the cotton or other cellulosic fibers. These dyes applied to cellulosic fibers are characterized by their excellent washfastness. ${ }^{[2]}$

In production processes, after the dyeing of textiles, many chemical finishing agents are used to provide the textile products with desired functional and aesthetic properties. Various kinds the fiber softeners, antistatic agents, wet-fastness improvers for dyed textiles, and water repellents are commonly used. $^{[1]}$ Detection of the presence of the abovementioned chemical finishing agents has an important practical (and technological and commercial) aspect. This issue is also important from the scientific and analytical point of view, especially in analysis of textile materials in the form of fiber traces, for forensic purposes.

A review of the published literature indicates that the identification of dyes present in a forensic fiber trace by FTIR is mostly impossible because of their too-low concentration, but the dye or pigment signals are usually dominant in the Raman spectrum. ${ }^{[3]}$ In recent years, developments in Raman instrumentation have made this technique more attractive for analytical and forensic use. The development of FT-Raman and use of near-IR excitation wavelengths have reduced the problem of fluorescence. Most of the forensic laboratory instruments are equipped with several different excitation lasers, allowing selection of the most appropriate excitation line and minimization of fluorescence and photodegradation of the given sample. ${ }^{[3]}$ The results obtained with the use of Raman spectroscopy show that the detection limit is dependent on the excitation wavelength, but even if the same excitation source is used, this limit depends on the instrument, the experimental conditions, and the operator. ${ }^{[4]}$

In most reports on the Raman spectroscopy of colored fibers, the problems of fluorescence were noted, ${ }^{[4,5,7]}$ even though this technique was regarded as the only one that can almost nondestructively provide molecular structural information about the dye in the fiber and pigments. ${ }^{[4-9]}$ Pigments present in textile materials are usually easily detected and can be identified using a reference database, but the identification of dye or dyes is a very complex problem. ${ }^{[4]}$ Raman spectroscopy can also be used to identify fiber classes and subclasses, especially the colorless ones, often indistinguishable by the FTIR method (e.g., man-made cellulose fibers and natural vegetable fibers). ${ }^{[10-12]}$

Resonance Raman spectroscopy, as an improvement of the conventional method, theoretically reveals increased sensitivity and selectivity and, so, is better suited for examinations of the compound materials such as black dyed fibers. ${ }^{[9]}$ A potential disadvantage of resonance conditions that exists when a laser wavelength coincides with the UV-visible absorption band of the sample can result in strong fluorescence emission. The use of conventional nonresonance Raman scattering equipped with lasers of different excitation wavelengths and the selection of the appropriate measuring conditions can help to avoid 
fluorescence problems, but it strongly depends on the sample itself.

The present study aimed to evaluate the degree of discrimination between cotton and viscose fibers, being dyed with several dye classes, using Raman spectroscopy. This type of comparative analysis of two kinds of dyed cellulosic fibers has not been the subject of literature reports so far. The distinction of different types of fibers (cotton and viscose) dyed with the same dye, at the same or very similar concentrations, has not been studied either.

The main purpose of the research was to study the influence of the laser beam wavelength, the dye and selected chemical agent concentrations, and the type of dyed fibers on the obtained Raman results. Explanation of these relationships will be useful for the identification of the cellulosic textile product from which the examined fibers have been separated. A point-by-point microscopical and Raman comparison provides the most discriminating method of determining if two or more fibers consistently originate from the same source.

\section{EXPERIMENTAL Materials}

\section{Woven Fabrics}

Two woven fabrics from cellulosic fibers are used in the study: the cotton fabric scoured and bleached (with hydrogen peroxide) supplied from the factory Andropol S.A. (Andrychow, Poland) and the viscose fabric purchased from the Society of the Polish Chemists and Colorists (Lodz, Poland).

Cotton and viscose fabrics used in this study contained no dyes, auxiliary agents, or optical brightening agents. Cotton fabric parameters were mass per unit area: $130 \mathrm{~g} / \mathrm{m}^{2}$; thickness: $0.29 \mathrm{~mm}$; and viscose fabrics, respectively: $110 \mathrm{~g} / \mathrm{m}^{2}$ and $0.23 \mathrm{~mm}$.

These fabrics after dyeing and/or finishing processes were the source of single fibers as the objects of investigation by Raman spectroscopy.

\section{Dyes and Chemical Finishing Agent}

Eight reactive and six direct dyes and one chemical finishing agent were used in this study.

Novacron $F$ is the amino-fluoro-s-triazine, monofunctional reactive dye. Novacron $\mathrm{FN}$ is the bifunctional monofluorotriazine-sulfatoethylsulfone dye. Both Novacron F and Novacron FN dyes are used above all to dye cellulose fibers.

The values for the content of dyes in samples of cotton and viscose fabrics are presented in Table 1. The dyeing process and the method for determining dye concentrations in textile samples are described in the next section, "Dyeing and Finishing Fabric Samples."

The criterion for the determination of the quantity of dyes and chemical agent applied to samples of fabrics in the dyeing and finishing processes was the

TABLE 1 Dye Concentrations in Fabric Samples from Which the Individual Fibers for Raman Analysis were taken

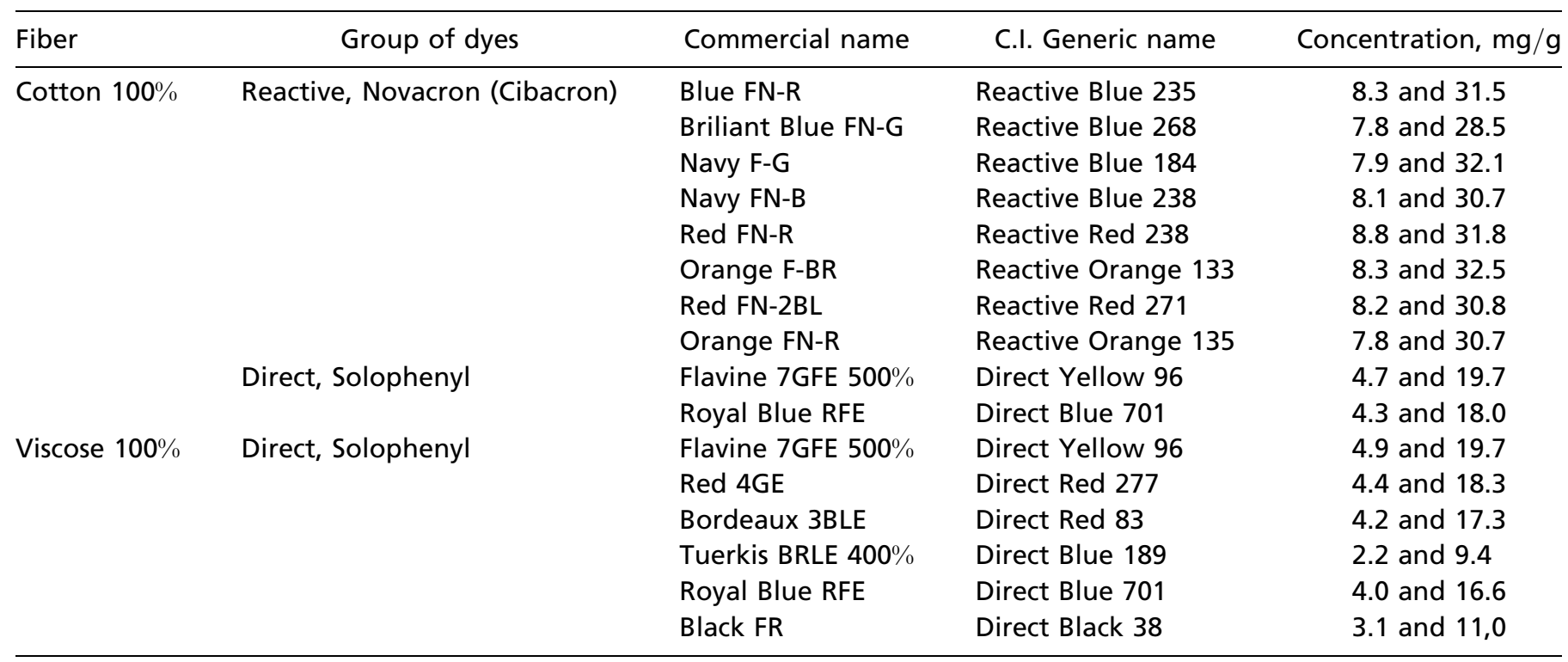


range of technological concentrations recommended by the manufacturer.

Both dyes and finishing agents were kindly provided by Huntsman Advanced Materials (Switzerland).

\section{Dyeing and Finishing Fabric Samples}

The laboratory dyeing apparatus (UGOLINI Redkrome, Italy), equipped with infrared heating, at a liquor ratio of 50:1, was used throughout this work. Dye concentration in dyed fabric samples was determined using a UV-Vis-NIR Jasco V-670 spectrophotometer. The dye-bath samples were taken at the start and at the end of each dyeing process, and their absorbance values were measured at the maximum absorbance wavelength. On the basis of these absorbance values before and after the dyeing process, the amount of dye in dyed fabric samples was calculated.

\section{Dyeing with Direct Dyes.}

The ready-to-dye cotton and viscose fabric samples ( $4 \mathrm{~g}$ ) were used. The dye baths contained a direct dye- $0.5 \%$ and $2.0 \%$ owf (on weight of fibers) - and appropriate amount of Glauber's salt (specified by the manufacturer of dyes). The process was started at $40^{\circ} \mathrm{C}$, the temperature was raised to boiling $\left(2^{\circ} \mathrm{C} / \mathrm{min}\right)$, and dyeing was continued at the same temperature for another $40 \mathrm{~min}$. The dyed fabric samples were rinsed with warm and cold water and then dried at ambient temperature.

\section{Dyeing with Reactive Dyes.}

The cotton fabric samples ( $4 \mathrm{~g}$ ) were dyed with monofunctional or bifunctional reactive dye. The dye bath contained a reactive dye ( $1 \%$ and $4 \%$ owf) and half of the appropriate amount of Glauber's salt (specified by the manufacturer of dyes). The dyeing process was started at room temperature and then the temperature was raised to $60^{\circ} \mathrm{C}\left(2^{\circ} \mathrm{C} /\right.$ min). The remaining amount of salt was added and the dyeing was continued at the same temperature for another $30 \mathrm{~min}$. Then the appropriate amount of soda ash was added into the dye bath and the process was continued for another $40 \mathrm{~min}$. Cotton samples were rinsed two times at $50^{\circ} \mathrm{C}$, neutralized with acetic acid, and soaped at $60^{\circ} \mathrm{C}$ for $20 \mathrm{~min}$ to remove the unfixed dyes. Finally, the fabric samples were dried at ambient temperature.

\section{After Treatment of Dyed Fabric Samples.}

Some samples of dyed cotton and viscose fabrics were aftertreated with Albafix WFF in a dip-nip application technique. The fabric samples were padded to about $100 \%$ wet pickup with an aqueous solution of this finishing agent (concentrations of $45 \mathrm{~g} / \mathrm{L}$ ). Padded samples were dried in a laboratory dryer at a temperature of $55^{\circ} \mathrm{C}$ for $5 \mathrm{~min}$. The Albafix WFF content in the fabric samples was determined on the basis of wet pickup and concentration of this agent in the aqueous solutions used in the padding process. This content of Albafix WFF in the cotton and viscose samples was about $45 \mathrm{mg} / \mathrm{g}$.

\section{Method}

The fibers taken from dyed and/or finished fabrics were the subject of Raman examinations. Raman spectra were obtained using a Renishaw inVia spectrometer equipped with a confocal Leica microscope and three types of excitation sources: Ar ion $(514 \mathrm{~nm}), \mathrm{He}-\mathrm{Ne}(633 \mathrm{~nm})$, and a near-infrared semiconductor laser $(785 \mathrm{~nm})$. The laser beam was

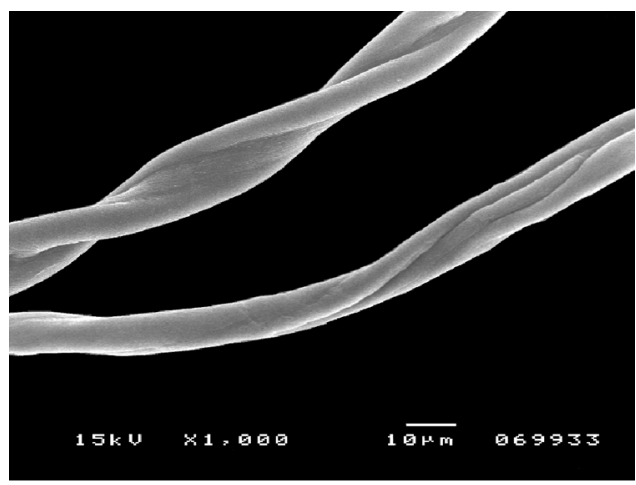

(a)

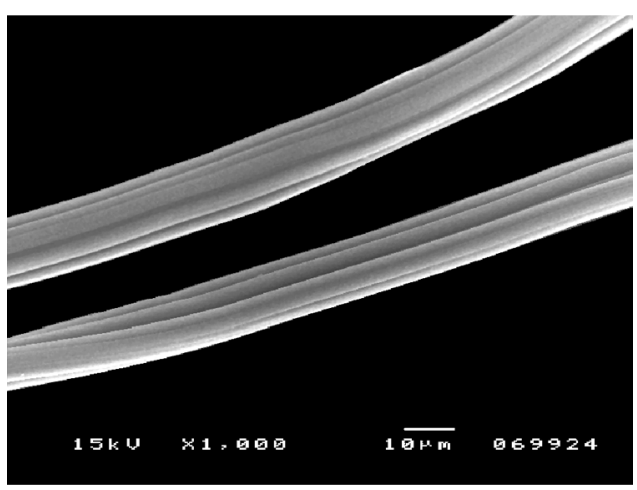

(b)

FIGURE 1 SEM images of examined (a) cotton and (b) viscose fibers. 
focused on the samples by a $50 \times$ objective lens. The signal was recorded using a Peltier-cooled chargecoupled device (CCD). Spectra were acquired with five accumulations, while the most suitable scanning times were determined experimentally for each test sample separately, as well as the laser's power, so that the received spectra were the best quality as to the intensity of the bands, their degree of separation, and their signal-to-noise ratio. After each measurement, the place on the fiber where the laser beam was focused was observed in order to check whether or not there had been any damage to the fibers. Spectra were acquired in the range of $200-1800 \mathrm{~cm}^{-1}$; the spectra presented in this publication were baseline corrected and smoothed using Wire 3.2 software.

All the fabrics were dyed in their entirety; however, measurements were performed separately for the fibers extracted at random from the weft and from the warp of the fabric. Fibers were placed above an opening in an aluminum spectral plate. Selected fibers were attached to the plate by their ends, using adhesive tape, passing through the hole in the plate, and were well tightened. Fiber spectra were collected in three randomly selected locations. Focusing of the laser beam on the viscose staple fibers was hampered due to their extended surface area (Fig. 1), and therefore developing the optimal conditions for measurement of these fibers was a very time-consuming process.

Dyes were converted into aqueous solutions, and drops were deposited onto glass slides covered with aluminum foil (to diminish the impact of the glass background) and dried before analysis.

All spectra were scanned in a longitudinal position, parallel to the electric vector of the incident light.

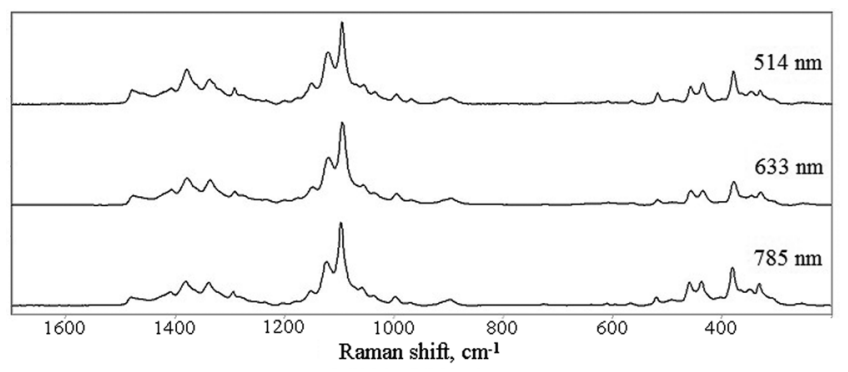

FIGURE 2 Comparison of Raman spectra of uncolored cotton fibers obtained with the use of different laser wavelengths $(514 \mathrm{~nm}, 633 \mathrm{~nm}, 785 \mathrm{~nm})$.

\section{RESULTS AND DISCUSSION \\ The Impact of the Wavelength of the Used Laser}

Raman spectra obtained for uncolored cotton fibers at the excitation lines $514 \mathrm{~nm}, 633 \mathrm{~nm}$, and $785 \mathrm{~nm}$ (Fig. 2) in the region of $200-1800 \mathrm{~cm}^{-1} \mathrm{did}$ not show differences in the number of bands; they could be only shifted by less than $5 \mathrm{~cm}^{-1}$. Similar results were obtained for the uncolored viscose fibers.

Obtained Raman spectra of cotton and viscose fibers could be divided into two regions: 1750$800 \mathrm{~cm}^{-1}$ and $610-200 \mathrm{~cm}^{-1}$. The literature study indicated that the bands in the first region were related mainly to skeletal, symmetric, and asymmetric glycosidic ring breathing (at 1096 and $\left.1121 \mathrm{~cm}^{-1}\right)$, methylene $\left(\mathrm{CH}_{2}\right)$ bending, rocking, and wagging (at 1460, 1375, 1336, and $996 \mathrm{~cm}^{-1}$ ). ${ }^{[12,13]}$ The second region is characterized predominantly by CCC and COC ring deformation (at 458, 377, 349 , and $330 \mathrm{~cm}^{-1}$ ). The primary difference between spectra of viscose and cotton fibers was found due to the presence in the first one of two strong bands at $898 \mathrm{~cm}^{-1}$ (HCC, HCO bending) and at $350 \mathrm{~cm}^{-1}$ (CCC bending), whereas their intensity in the spectrum of cotton is weak.

Examination of cotton and viscose fibers dyed experimentally (Table 1) confirmed that the number, position, and intensity of bands in the spectra obtained with the use of different laser wavelengths are not the same because of a different sensitivity and spatial resolution of the used lasers and, most of all, the specific sample behavior. As an example, cotton fibers dyed by Reactive Blue $238(30.7 \mathrm{mg} / \mathrm{g})$ examined with the use of different laser wavelengths

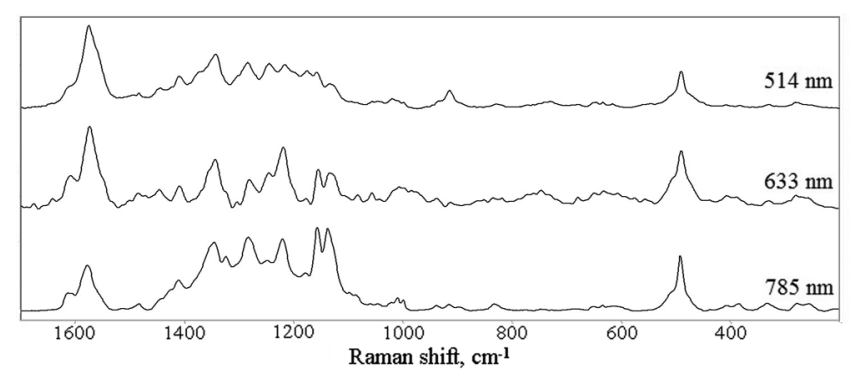

FIGURE 3 Comparison of Raman spectra of cotton fibers dyed by Reactive Blue $238(30.7 \mathrm{mg} / \mathrm{g})$ obtained with the use of different laser wavelengths $(514 \mathrm{~nm}, 633 \mathrm{~nm}, 785 \mathrm{~nm})$. 


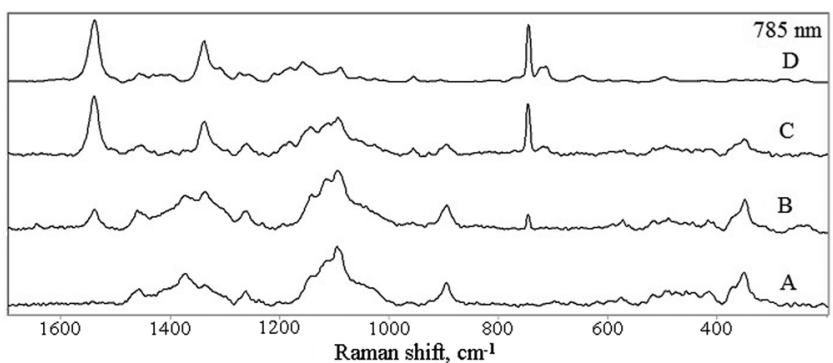

FIGURE 4 Raman spectra of viscose fibers (A), viscose fibers dyed with Direct Blue 189: $2.2 \mathrm{mg} / \mathrm{g}$ (B) and $9.4 \mathrm{mg} / \mathrm{g}(C)$, and viscose fibers dyed with Direct Blue 189 (D), recorded using the 785-nm laser line.

is presented (Fig. 3). In this case, the spectra obtained with the use of different lasers were not the same; the changes were mainly connected to the intensity of the bands.

\section{The Influence of the Concentrations of Dye and Selected Additives in the Fiber}

In most spectra of dyed cotton and viscose fibers, a relationship between the intensity of the Raman bands and the concentration of the dye in the fibers was observed. As an illustration of this statement, the spectra obtained in the case of viscose fibers dyed by Direct Blue 189 are presented (Fig. 4). In the spectra obtained for fibers with a lower concentration of dye (equal to $2.2 \mathrm{mg} / \mathrm{g}$ ), bands originating from viscose were dominant (at 1460, 1374, 1098, 898, and $352 \mathrm{~cm}^{-1}$ ), while in the case of higher concentrations $(9.4 \mathrm{mg} / \mathrm{g})$, the majority of the bands were due to the dye (at 1541, 1341, and $748 \mathrm{~cm}^{-1}$ ). Also, in the case of higher concentrations of dye in the fiber, an increase in the intensity of the dye bands and

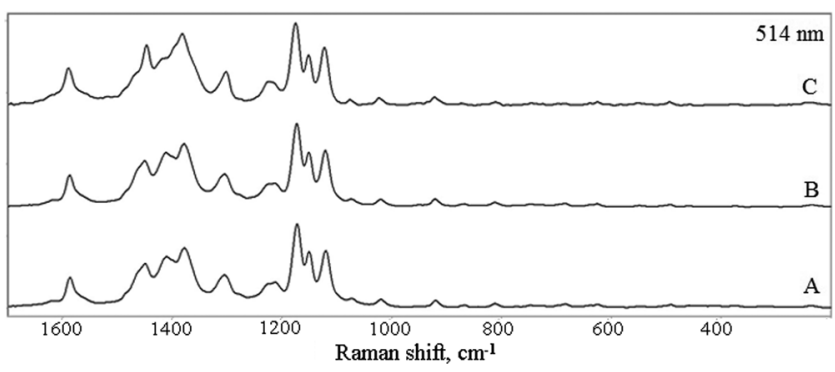

FIGURE 5 Raman spectra of cotton fibers dyed with Reactive Orange 133: $8.3 \mathrm{mg} / \mathrm{g}(\mathrm{A})$ and $32.5 \mathrm{mg} / \mathrm{g}(B)$, and the dye Reactive Orange $133(C)$, obtained using a laser with a wavelength of $514 \mathrm{~nm}$.

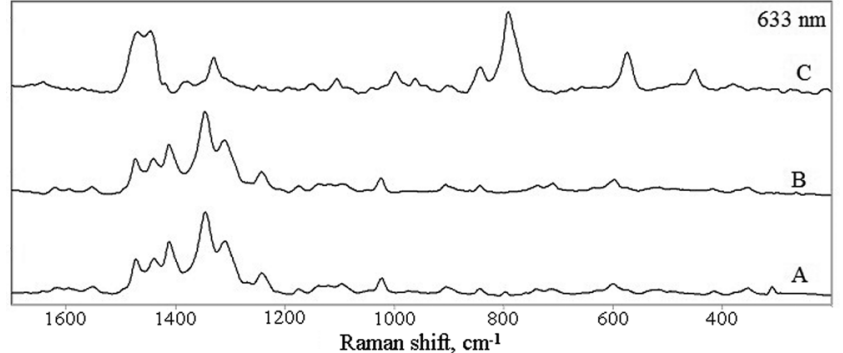

FIGURE 6 Raman spectra of viscose fibers dyed with Direct Red 83 (A), and the same fiber finished with Albafix WFF at a concentration of $45 \mathrm{mg} / \mathrm{g}(B)$, and Albafix WFF (C), recorded using the 633-nm laser line.

the emergence of some new bands (at $716 \mathrm{~cm}^{-1}$ ) were observed.

With the use of laser wavelengths of $514 \mathrm{~nm}$ or $633 \mathrm{~nm}$, in the spectra of dyed cotton and viscose fibers, no bands originating from cellulose were observed. In this case, the concentration of the dye did not directly affect the mutual relations of intensity of the characteristic dye bands, as shown in the example of cotton fibers dyed with Reactive Orange 133 (Fig. 5).

Figure 6 illustrates spectra obtained with the use of a laser wavelength of $633 \mathrm{~nm}$ for viscose fibers dyed with Direct Red 83 and the same type of fibers also containing a softening substance (Albafix WFF). Unfortunately, the spectra of fibers with and without the softening agent were very similar, and the bands characteristic for this finishing agent were not seen. The application of laser wavelengths of $514 \mathrm{~nm}$ and $785 \mathrm{~nm}$ did not result in the appearance of the bands characteristic for Albafix WFF.

Most likely, the properties of this softener are such that its detection would be possible when it is present within the fiber in higher concentrations.

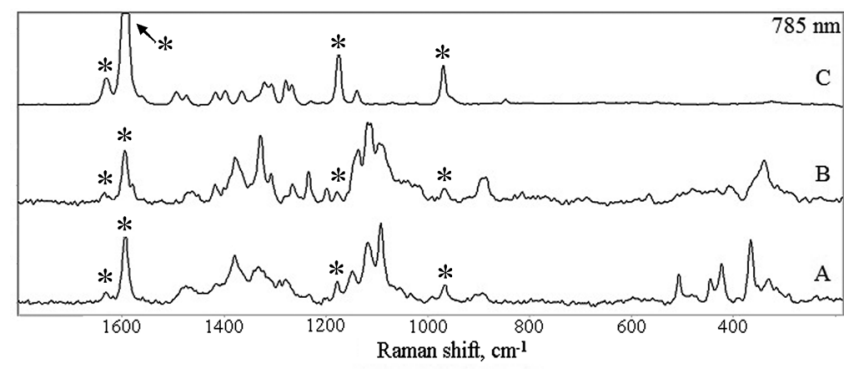

FIGURE 7 Raman spectra of cotton fibers dyed with Direct Yellow 96: $19.7 \mathrm{mg} / \mathrm{g}(\mathrm{A})$, viscose fibers dyed with the same dye and concentration (B), and the dye Direct Yellow 96 (C), recorded using the 785-nm laser line. Asterisks indicate bands coming from the dye. 


\section{The Impact of the Type of Dyed Fiber}

Analysis of the spectra obtained for uncolored cotton fibers and uncolored viscose fibers dyed with Direct Yellow 96 showed that the bands originating from the fibrous material and from the dye are present at the same time. The comparison of spectra obtained for cotton and viscose fibers dyed at the same concentration $(19.7 \mathrm{mg} / \mathrm{g})$ with the aforementioned dye allowed demonstration of the differences resulting from the kind of dyed material (Fig. 7). The presence of strong bands at $898 \mathrm{~cm}^{-1}$ and $350 \mathrm{~cm}^{-1}$ allows differentiation of viscose from cotton.

A similar relationship was not observed, for example, in the case of blue cotton fibers and viscose fibers dyed with Direct Blue 701, as only bands from the dye were observed in the Raman spectra of both fibers.

\section{Other Observed Relations}

Before proceeding to the Raman study of cotton and viscose fibers, it was necessary to choose the appropriate measurement parameters for each examined fiber independently. Parameters such as the way the sample was prepared, the extent in which the fiber was collected, magnification of the microscope lens, and the number of accumulations stayed identical, but the type of the laser applied and its power and time impact on the sample were tested before each measurement.

Measuring parameters, as well as the way the sample was prepared and the form in which the dyes were examined (powder or liquid) had an important impact on the quality of the received spectra. The spectrum with the lowest band intensity as well as the smallest degree of separation between the bands was obtained by experimentally placing the fiber on the primary microscope slide and covering it with a coverslip, similar to the classic microscopic studies of fibers. The best results were received while placing the fiber on an aluminum spectral plate or on an aluminum foil-coated microscope slide.

In the course of testing cotton and viscose fibers, it was found that the intensity of the Raman bands depend on the location of the laser beam on the fiber. Most probably, this is due to the extended surface of viscose fibers and the specific geometric form of cotton fibers. In the course of the measurement, difficulties emerged with focusing the laser beam on the surface of the viscose fibers (Fig. 1), thus affecting the quality of the obtained spectra and the duration of their analysis.

During the measurements, cotton and viscose fibers were characterized by relatively high stability and infrequent localized burning of the fibers as a result of the interaction with the laser. The cause of this phenomenon is usually due to too much laser power, the duration of the laser's exposure with the sample, or too-low thermal resistance of particular fibers.

In the course of investigations, it was noted that there is a relationship between the values of certain measurement parameters and the color of the examined fiber. For the uncolored fibers and fibers dyed with bright, less intense colors (e.g., yellow, orange, pink), the best-quality spectra were obtained using a laser power ranging from $50 \%$ to $100 \%$. In contrast, for the dyes giving dark coloring, goodquality spectra were usually received by applying the laser power in the range from $1 \%$ to $10 \%$. For part of the samples dyed by the same dye but at varying concentrations, it was observed that for the same excitation line, the best-quality spectra of samples with low concentrations of dye were received with more laser power. The application of an aluminum plate as the base on which fibers were placed allows the measurements at a higher laser power, compared with measurements performed on fibers of similar colors placed on a microscope slide.

Fluorescence was an unfavorable phenomenon accompanying certain measurements. This made it impossible to obtain good-quality spectra. The severity of this phenomenon was different; where the fluorescence was intense, the bands on a spectrum were obscured, making it difficult to interpret. When the fluorescence was less intense, a small portion of information about the sample was obtained. In the case where the dye in the fiber showed fluorescence (in studies of several reactive dyes), the power of the laser typically ranged between $1 \%$ and even $0.0001 \%$. The fluorescence was not observed in the case of uncolored fibers for the applied excitation lines, despite the fact that all measurements were made at the maximum laser power. The lack of fluorescence in the case of uncolored fibers indicated that fluorescence present 
in the spectra of dyed fibers was caused by the dye. On the other hand, by analyzing the results obtained for the cotton fibers dyed by reactive dyes and for the reactive dyes itself (Reactive Blue 238 and Reactive Red 238), it was found that fluorescence can occur as a result of the binding of a dye within a fiber. This can be demonstrated by good-quality spectra of reactive dyes-Reactive Blue 238 (lasers: $514 \mathrm{~nm}, 633 \mathrm{~nm}, 785 \mathrm{~nm}$ ) and Reactive Red 238 (lasers: $514 \mathrm{~nm}, 785 \mathrm{~nm}$ )—and enclosure of certain spectral bands in the spectra of fibers dyed with these dyes (e.g., laser $633 \mathrm{~nm}$ ).

As mentioned above, during the studies of uncolored cotton and viscose fibers carried out by applying lasers with wavelengths of 532, 633, and $785 \mathrm{~nm}$, no fluorescence was observed. This remains in contrast with other groups' examination reports, which observed fluorescence during the measurement of uncolored cotton fibers using a laser with a wavelength of $514 \mathrm{~nm}^{[8]}$

An $\mathrm{Ar}$ ion laser $(\lambda=514 \mathrm{~nm})$ was capable of producing information on dyes present in the analyzed cotton fibers. In the spectra of more than $80 \%$ of dyed cotton samples, only the bandwidth from the dyes were present, whereas in the case of the other cotton samples, the spectral bandwidth of cellulose also occurred.

In the case of cotton fibers examined by using a laser with a wavelength of $633 \mathrm{~nm}$, bands coming exclusively from the dye appeared in 50\% of the received spectra, whereas in the case of a laser with a wavelength of $785 \mathrm{~nm}$, this occurred in only about $30 \%$ of the spectra. For most of the remaining cotton fiber samples, the spectrum bands originating from the dye and from cellulose occurred at the same time. The presence of cellulose bands was observed in only $14 \%$ of spectra obtained for fiber samples (purple, orange, and yellow) using a laser with a wavelength of $785 \mathrm{~nm}$.

\section{CONCLUSIONS}

In the procedure of cotton and viscose fiber identification, Raman spectroscopy should always be preceded by optical microscopy examinations. While using Raman spectroscopy, the selection of the appropriate measuring conditions and the application of many excitation laser wavelengths enabled the analysts to identify specific components, mainly dyes, present in the samples and very often to avoid fluorescence.
Even the use of an Ar ion laser ( $514 \mathrm{~nm}$ ) generated information about the dyes present in the dyed cotton fibers; the presence of dye bands only was confirmed for more than $80 \%$ of the obtained spectra.

The Raman spectral response of a dye varied depending on the dye itself and its concentration in the textile material. It was found that in certain cases, Raman spectroscopy allows the differentiation between cotton and viscose fibers dyed with the same dye, at the same or very similar concentrations.

In the spectra of fibers with a lower concentration of dye, bands originating from cotton and viscose were usually predominant, while in the case of higher concentrations of dye, the majority of the bands originated from the dye. However, not in every case did the concentration of the dye in cotton and viscose fibers directly affect the mutual relationships between the intensities of characteristic dye bands and their concentration in the fiber samples. This phenomenon depended mainly on the kind of the examined samples.

Because of the availability of thousands of dyes for textiles on the market, databases are needed to make them easier to identify. On the basis of the presented study, the creation of databases of spectra obtained for the examined cotton and viscose fibers, dyed with known types and concentrations of dye, was started. During the creation of our databases, various laser wavelengths were used $(514,532$, and $785 \mathrm{~nm})$, contrary to the commercial databases, which were created mainly with infrared lasers.

\section{ACKNOWLEDGMENTS}

The authors would like to thank Mrs. Karolina Tulak and Mrs. Martyna Lesniewska, students of the Chemistry Department of the Jagiellonian University in Krakow, for their technical support with the Raman technique.

\section{FUNDING}

The research was financially supported by The National Centre for Research and Developmentproject number O N204 115036.

\section{REFERENCES}

1. Rouette, H. K. Encyclopedia of Textile Finishing, 4th ed; Springer: Berlin, Germany, 2001.

2. Vigo, T. L. Textile Processing and Properties; Elsevier Science B.V.: Amsterdam, The Netherlands, 1994. 
3. Chalmers, J. M.; Edwards, H. J.; Hargreaves, M. D. Infrared and Raman Spectroscopy in Forensic Science; John Wiley and Sons Ltd.: Chirchester, UK, 2012.

4. Massonnet, G.; Buzzini, P.; Monard, F.; Jochem, G.; Fido, L.; Bell, S.; Stauber, M.; Coyle, T.; Roux, C.; Hemmings, J. Raman spectroscopy and microspectrophotometry of reactive dyes on cotton fibres: Analysis and detection limits. Forens. Sci. Int. 2012, 222, 200-207.

5. Massonnet, G. Raman analysis of textile fibres. In Manual of Best Practice for the Forensic Examination of Fibres, 2nd ed.; Massonnet, G., Ed.; Bundeskriminalamt: Wiesbaden, 2012.

6. Massonnet, G.; Buzzini, P.; Jochem, G.; Stauber, M.; Coyle, T.; Roux, C.; Thomas, J.; Leijenhorst, H.; Van Zanten, Z.; Wiggins, K. G. Evaluation of Raman spectroscopy for the analysis of coloured fibres: a collaborative study. J. Forens. Soc. 2005, 50, 1028-1038.

7. Thomas, J.; Buzzini, P.; Massonnet, G.; Reedy, B.; Roux, C. Raman spectroscopy and the forensic analysis of black/grey and blue cotton fibres: Part. 1. Investigation of the effects of varying laser wavelength. Forens. Sci. Int. 2005, 152, 189-197.

8. Lepot, L.; De Wael, K.; Gason, F.; Gilbert, B. Application of Raman spectroscopy to forensic fibre cases. Sci. Justice 2008, 48, 109-117.

9. Abbott, L. C.; Batchelor, S. N.; Smith, J. R.; Moore, J. N. Resonance Raman and UV-visible spectroscopy of black dyes on textiles. Forens. Sci. Int. 2010, 202, 54-63.

10. Eichhorn, S. J.; Young, R. J.; Davies, R. J.; Riekel, C. Characterisation of the microstructure and deformation of high modulus cellulose fibres. Polymer 2003, 44, 5901-5908.

11. Edwards, H. G. M.; Farwell, D. W.; Webste, D. FT Raman microscopy of untreated natural plant fibres. Spectrochim. Acta Part A 1997, 53, 2383-2392.

12. Kavkler, K.; Demšar, A. Examination of cellulose textile fibres in historical objects by micro-Raman spectroscopy. Spectrochim. Acta Part A 2011, 78, 740-746. 